\title{
Artificial Bee Colony Based MPPT Technique for Solar PV System Under Partially Shaded Condition
}

\author{
L Venkata Subba Reddy
}

\begin{abstract}
Energy recovery circuit plays significant role in $P V$ string, during different irradiance value condition of PV modules. The BBCSC circuit is the combination of buck-boost converter and switched capacitor circuit; used to eliminate bypass diodes. The main objectives of BBCSC circuit are energy recovery from the photovoltaic modules under different irradiance value condition of PV modules and the voltage of the PV string is maintained on the level generated. In this paper, artificial bee colony (ABC) optimization technique is implemented with MPPT algorithm for solar modules string with boost converter and energy recovery circuit; to improve maximum output power and voltage values during PSC. The main limitation in the conventional method is to track exact MPP under partially shaded condition (PSC) is not satisfactory and Sometimes takes local maxima as global maxima. To overcome this, a new proposed artificial bee colony (ABC) algorithm MPPT is implemented. Comparative analysis has been carried out and verified between the above of state of art methods through simulation results.

To valid and verify the effectiveness of the proposed BBCSC circuit, simulation results are presented in MATLAB/Simulink software.
\end{abstract}

Keywords: Buck-boost converter(BBC), artificial bee colony $(A B C)$, partially shaded condition(PSC), switched capacitor(SC), photovoltaic ( $P V)$, maximum power point (MPP)

\section{INTRODUCTION}

Photovoltaic (PV) energy system[1] development increases throughout world day by day due to main source of the photovoltaic system is the sun rays. they are completely free of cost and also environment friendly but major problem in the photovoltaic (PV) system is the partial shading condition (PSC) [3]. Partial shading condition mainly occurs due to shadow of tall buildings in the urban areas and tall trees and also clouds formation during rainy season. Photovoltaic system is a series-parallel combination of photovoltaic module arrangement. Whenever, shadow place on the array irradiance of particular array reduced due to this output energy of the array reduces. Sometimes partially shaded array act as load instead of generation. partially shaded condition(PSC) plays significant role in the photovoltaic system towards reduction of efficiency and hotspot formation in the shaded arrays if left unprotected solar modules get severe problem. Typically, every module

Revised Manuscript Received on December 30, 2019.

* Correspondence Author

L Venkata Subba Reddy, M.Tech Scholar Electrical \& Electronics Pradesh, INDIA. Email: lvsubbareddy5@gmail.com

(c) The Authors. Published by Blue Eyes Intelligence Engineering and Sciences Publication (BEIESP). This is an open access article under the CC BY-NC-ND license (http://creativecommons.org/licenses/by-nc-nd/4.0/) Engineering, JNTUA College of Engineering, Ananthapuramu, Andhra in the arrays consist of bypass diode to change way of
current in the condition of

partial shaded effect. However, bypass diode activated, the photovoltaic I-V characteristics shows multiple local peaks along with one good efficient global peak. If photovoltaic (PV) system equipped with conventional maximum power point tracking (MPPT) such as perturbed and observed (P\&O) [6], increment conductance (IC) or Hill-climbing (HC), it will be grim to get maximum power point (MPP) peak because these conventional algorithms would not distinguish between the local peak and global peak in major cases MPPT will settle at local peak by reason of resulting huge power loss occurs in the solar string system. Besides huge amount of current flow in bypass diode conduction losses occurs and also debasing systems efficiency. Whenever full shaded condition occurs in the array it will act as a load in its place of generation all arrays arranged in a parallel combination voltage mismatch place in the system due to these mismatched condition system does not get maximum extractable power even complex methods such as optimal methods are used. Several topologies are available to extract power from shaded arrays during PSC 1 . One of the major topology of MPP is the energy recovery circuit topology.in this topology shaded PV system module current remunerated by remain healthy PV system module current to get closer MPP. energy recovery topology methods mainly consist of energy storage elements like inductor and capacitor. Even though only one storage element used in the system complexity and controllable number of elements like switches and diodes difficult to maintain voltage level of all arrays with different irradiance values. multitasked buck-boost converters is proposed to recover MPP, at the time of modules in the PSC condition. The voltage and current rating of power electronics equipment's like diode and switches and also inductor rating increased number of modules in the PV system string increases rating and complexity of the equipment's.

Switched capacitor (SC) equipped with PV array system to recover MPP during PSC is the one of the energy recover topology. switched capacitor circuit design have different types based on elements connected in the system. The SC [7] is a small electronic component. It operated by moving charges into capacitors and outside of capacitors when switches are in to and pro motion. Generally non coinciding signals are used in the switching process. These capacitors shift charges among each other in a array string. 
when the storage elements are switched backward and forward recurrently voltages of all arrays get same value near to each other form equalized voltage for all series combination of arrays in string.

The voltage equalization of string indecent on the capacitor value and speed of operation. The storage element value not appropriated to final output, but related to simply charge distribution among themselves. In the SC circuit switches definitely not at all produce voltage drop when the current reaches to zero his method to be prolonged to large number of arrays in the string with series connection, like $\mathbf{N}$ number of arrays in the string $\mathbf{N}-\mathbf{1}$ number of storage elements are used in the SC circuit design to perform operation. SC circuit design and operation is simple, but we consider maximum number of modules in the string it requires more number of capacitors and inductors also more components this is the main disadvantage in SC circuit energy recovery method. Higher components in the string increases complexity in the operation and SC circuit uses more number of capacitors when the circuit design consist of more number of modules in the string, more switched capacitors increases the cost of the circuit design.

In this proposed method, to extract MPP during PSC merging both power electronic device buck - boost converter and switched capacitor (BBCSC)[1] construction. This BBCSC circuit consist of less number of passive elements due to this almost compromises lossless during unshaded condition under healthy irradiance condition. basically BBCSC design consist less number of switches compared to both each individual circuit designs. So complexity of operation reduces and also this circuit consist of low current rating components. The explanation of the proposed method is dividing into frontward and regressive energy transference using both buck-boost converter and SC circuits, correspondingly. In the BBCSC circuit both buck-boost converter and SC circuit operations are explained in the one circuit with different switching process.

In the $\mathrm{ABC}$, artificial bees are mainly used to get fit food(solution). These bees are three types employ bees, onlooker, scouts. Employ bees are used for the search food source, onlookers waiting for employ bees source conformation, scouts confirm the food is fit or not. Finding the source information simple in ABC compared to other complex optimization algorithm.

\section{BUCK BOOST CONVERTER AND SWITCHED CAPACITOR CIRCUIT}

The BBCSC circuit shown in Fig 1. It consist of five PV modules. All modules are connected in series manner. from the dark black color components L1, L2, L3 and L4,S1,S2,D2,D4 completely used in the buck-boost circuit. but D3, D6, S2, S4, C13, C35 components are used for both buck-boost circuit and SC circuit. circuit shows the components like switches, diodes and capacitors connection to perform buck-boost operation at the time of PSC extract energy from the shaded modules and switched capacitor operation also perform during PSC with presence of PSC very complicated to recover energy from the shaded PV modules. earlier short circuited the shaded modules with bypass diodes across the modules it wasted all energy in the shaded modules. But the BBCSC create another path for the mismatched shaded modules and healthy modules current with energy storage elements. BBCSC circuit operate only during PSC, under healthy condition BBCSC circuit turnoff. Due to this there is no conduction and power loss during unshaded condition of the operation Whenever PSC occurs across any PV modules triggering circuit detect send signals to BBCSC circuit to turn on as soon as possible to raise voltage across shaded PV. perform both energy recovery methods with one circuit without requires extra components. For simple understanding total output energy represented with single constant current source.

The BBCSC circuit operated with bidirectional property like downward direction and upward direction. In this paper buck- boost converters are assign for downward direction energy transfer, that means consider fig 1 . PV numbers. Higher PV1 module gives higher irradiance(voltage) value compared to lower PV5 module. SC circuit assign to transfer energy upward direction. Buck-boost converter and SC circuit both consist of two modes of operation basically charging and discharging modes.

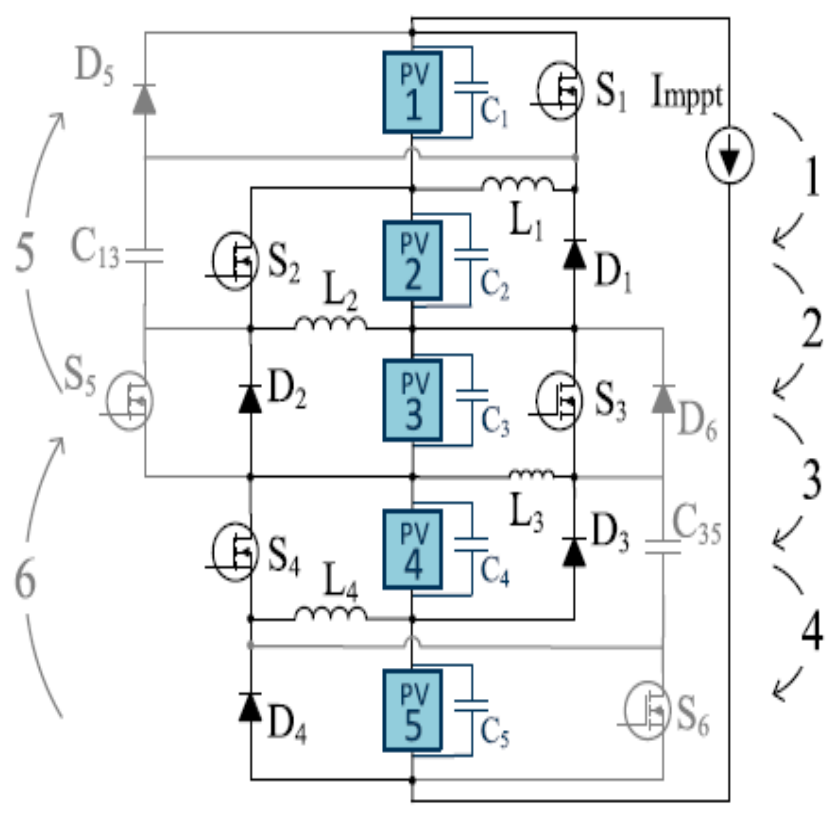

Fig 1. BBCSC circuit design (buck-boost circuit in dark black color, SC circuit in light black color) 


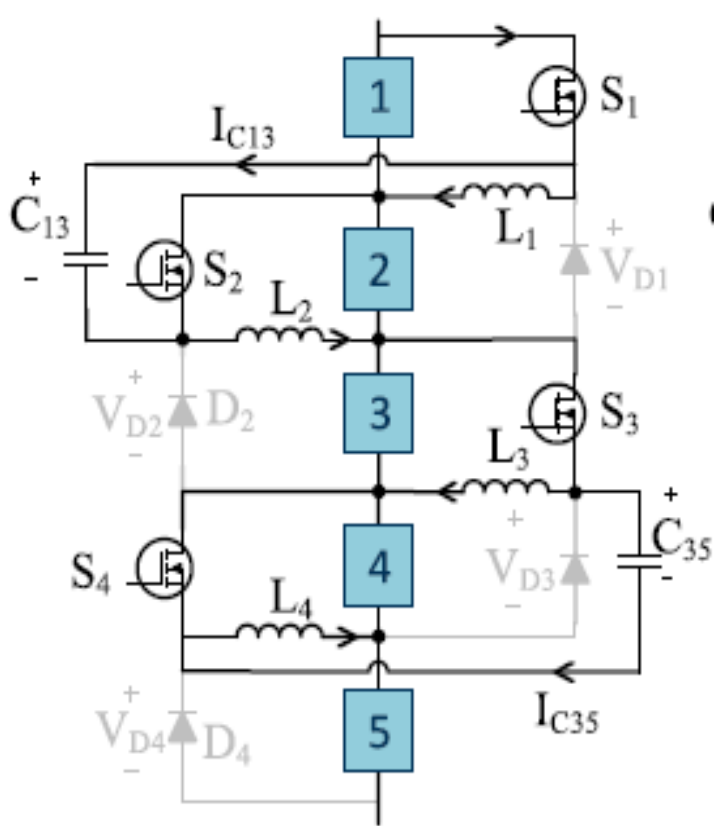

(a)

Fig 2. Buck-boost circuit (a) charging mode

\section{A. Buck-boost converter circuit}

Buck-boost circuit shown in Fig 1. With Dark black color. operation of buck-boost converter in BBCSC circuit in two modes charging and discharging modes along with two capacitors $\mathrm{C}_{13}$ and C35.

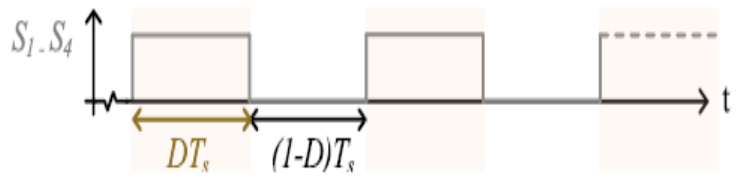

(a)

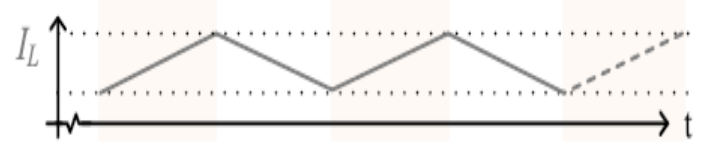

(b)

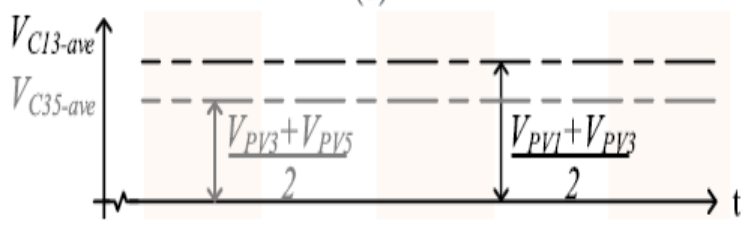

(c)

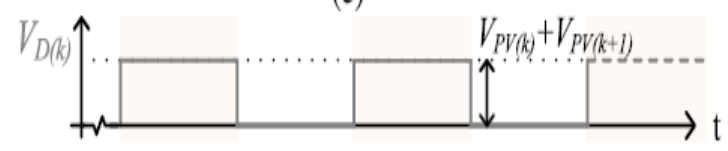

(d)

Fig 3. (a) Gate pulse signal (b) Inductor current (c) Capacitor voltages (d) Reverse conducting diode voltage.

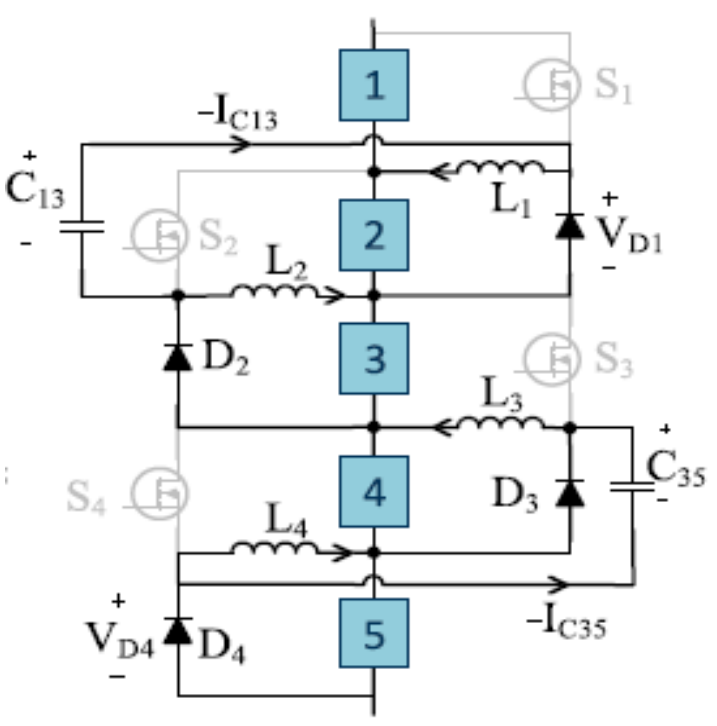

(b)

(b) discharging mode

buck-boost converter operation in downward energy transfer means, reduce irradiance values from higher module to lower module and also pulses, inductor current, diode and capacitor waveforms shown in the Figure.

1. charging mode of buck-boost converter

In the Fig 2(a) circuit consist of five modules in series connection across these modules four switches and four diodes and four inductors, two capacitors are present, in charging mode all diodes are in revere biasing condition but, all four switches s1 to s4 are in closed state due to this inductors are charged form linear current wave. In this mode energy transfer in downward way due to this top capacitor have high voltage compared to lower voltage

$$
\mathrm{I}_{\mathrm{L}}=-\frac{V_{P V}}{L} \mathrm{DT} \quad \mathrm{I}_{\mathrm{C}}=\frac{V_{P V}-V_{C}}{R}
$$

Here $\mathrm{I}_{\mathrm{L}}$ means inductor current and $\mathrm{V}_{\mathrm{PV}}$ indicate total $\mathrm{PV}$ module voltage, $\mathrm{L}$ is the inductor, $\mathrm{D}$ indicate duty ratio, $\mathrm{T}$ is the total time period

Here $I_{C}$ is average of two capacitors current $V_{C}$ is average capacitor voltage, $\mathrm{R}$ indicate switch equivalent resistance.

\section{Buck- boost converter discharging mode}

At the end of charging mode all switches are turn off. it takes half of time period. In this mode all diodes are turn on due to forward bias condition. Inductor discharge energy current also decreases linearly, due to this inductor current shows negative indication in the equation. 


$$
\mathrm{I}_{\mathrm{L}}=-\frac{V_{F V}}{L}(1-\mathrm{D}) \mathrm{T}
$$

In the complete buck-boost converter operation output voltage depend on duty ratio and input voltage from the energy conversion phenomenon buck-boost circuit has one output equation as follow

$$
V_{\text {out }}=\frac{D}{(1-D)} \mathrm{V}_{\mathrm{PV}}
$$

Depending on duty ratio buck boost converter act as a buck converter and boost converter.

\section{B. Switched capacitor circuit}

The switched capacitors are connected across PV modules in the string. Switched capacitors operation mainly, based on charge transfer among PV modules in the circuit from Fig 1. Light black color lines. SC circuit operated in two modes like BBC. Switches S1,S3 remains off entire operation. every switch has fixed $50 \%$ duty ratio.

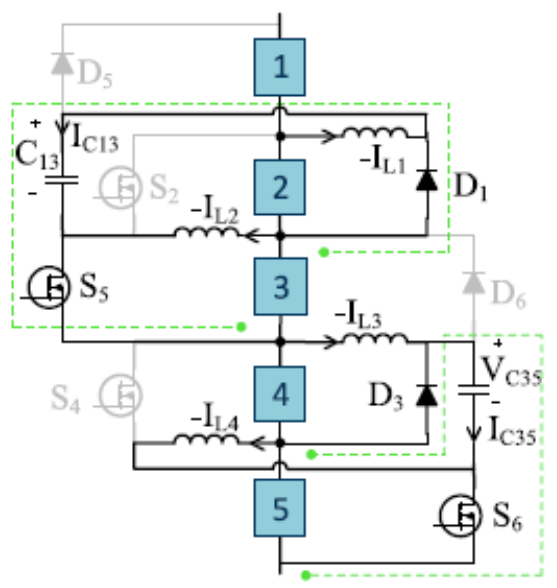

(C)

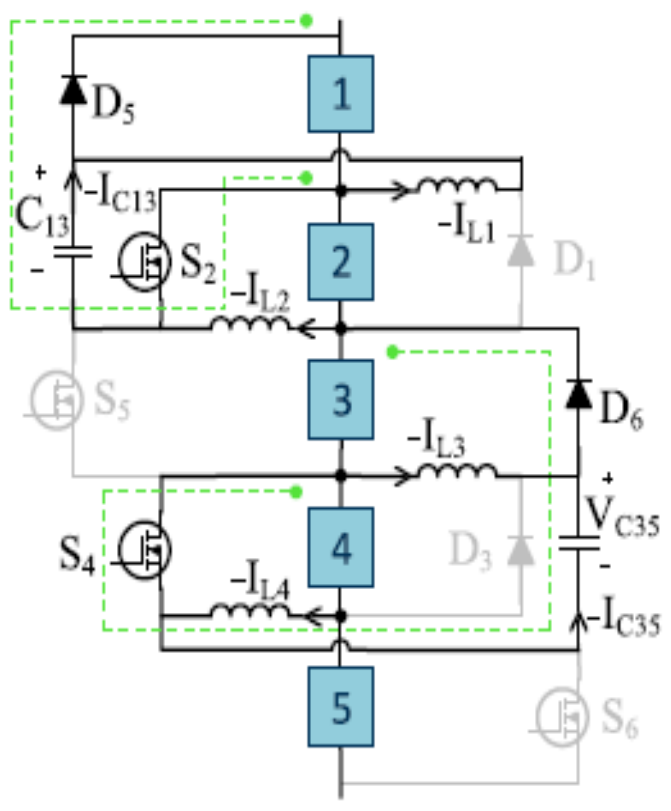

(D)

Fig 4. (C) SC circuit charging mode

(D) SC circuit discharging mode

1. SC circuit charging mode

In the SC circuit operation switches S2,S4,S5,S6 are plays main role. S2,S4 switches complementary with S5,S6 respectively. In the charging mode S2,S4 in turn off condition, S5 and S6 switches are in turn on condition diodes also in forward bias due to lower capacitor voltage compared to PV modules across it. capacitors are charged through inductors rise voltage linearly like shown in the figure. Diodes remain on in the circuit awaiting voltage reaches drop level voltage after that capacitors reaches full charge linearly. this operation similar to the BBC charging operation but in this circuit capacitors charge in place of inductors. Switched capacitors charge quickly compared to BB converter because in SC operation energy transfer through charge exchange between PV modules SC produce more level voltage during different irradiance condition.

2. SC circuit discharging mode

In the discharging mode switches S5 and S6 turn off. switches S2 and S4 receives pulses to turn on. also diodes D5 and D6 reaches forward biased condition. In this mode capacitors slowly decreases towards Lower value compared to module voltages finally reaches steady. Capacitor voltage value always taken as average voltage of the capacitor.

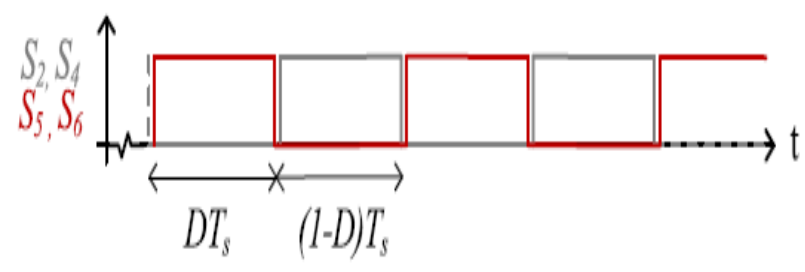

(a)

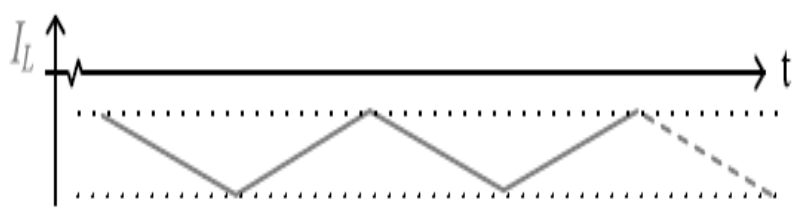

(b)

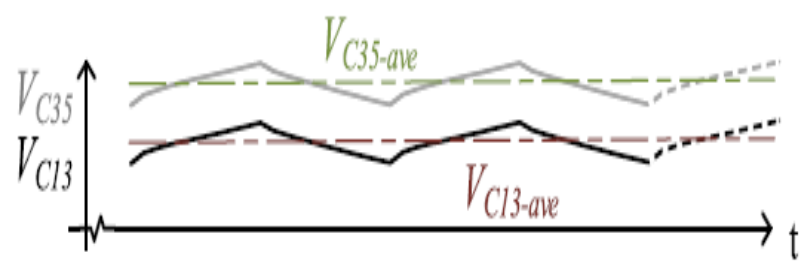

(c)

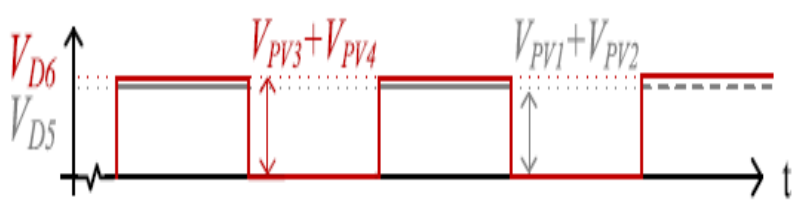

(d)

Fig 5. SC circuit (a) gate pulse signal (b) inductor negative current (c) capacitor voltage (d) diode voltages

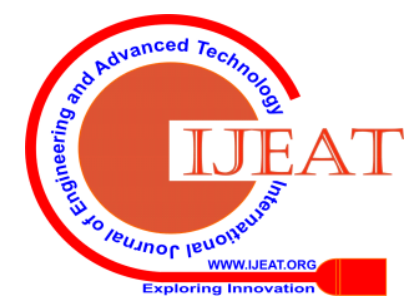




\section{PROPOSED MPPT CONTROLLER BASED ON ABC ALGORITHM}

The proposed Artificial bee colony optimization technique based MPPT is a new swarm intelligence technology algorithm. Especially bees have major characteristics like food source easily identified by the employed bees in simple ways. In the ABC optimization number of employed bees indicates the number of food sources means solutions and also sometimes number of onlookers are equal to the same number solutions. Onlookers identifies available fit solution then scout bees confirm these solution give better or not. Solution is not fit for problem again same operation performed until certain limit in the ABC algorithm. Bees have excellent characteristics like learn, fast sharing of information and memories location based on sun rays with angle of inclination. In the hive more number of bees are available each bees search gives one solution there is no overlapping and also more solutions takes less time compared to another techniques like PSO,ANC algorithm. ABC algorithm gives accurate results for complex problems. ABC algorithm effectively applied for major science field and also useful in the engineering services especially optimization technique plays major role in the design of mechanical design and automobiles. Basically this algorithm not depend upon PV characteristics of solar modules and also independent on converging conditions.

The ABC optimization technique used for MPPT in the solar system using direct control method. In this method, all bees solutions takes in the form of duty ratio for DC-DC circuit like boost converter. To get best solution always check voltage of PV module $V_{\mathrm{PV}}$ current $\mathrm{I}_{\mathrm{PV}}$ and power $\mathrm{P}_{\mathrm{PV}}$ with different duty ratios, scout bees fix fitness function for best optimal solution based on MPP duty ratios.

$$
\mathrm{di}=\mathrm{d} \min +\operatorname{ran}[0,1](\mathrm{d} \max -\mathrm{d} \min )
$$

new di=di $+\mathrm{i}(\mathrm{di}-\mathrm{dk})$

$$
P_{i}=\frac{P p v_{i}}{\sum_{n-1}^{S N} P p v_{i}}
$$

The ABC algorithm mainly performed by employed bees, if food source solution not better with trials food source leaved. then employed bee is changed into scout bee to improve accuracy of optimization using new duty cycle formulae.

\section{SIMULATION RESULTS}

In this segment, energy recovery circuit BBCSC used to recover maximum power during PSC in the PV string. PV string consist of five PV modules in series manner with different irradiance conditions simulated in the MATLAB/Simulink software. Conventional P\&O MPPT is used to search MPP of PV modules and boost converter is placed between PV string and load, but conventional P\&O method can't get global maxima point under PSC in simple manner sometimes local maxima taken as a MPP at that time loss some power. The proposed artificial bee colony(ABC) algorithm based MPPT gives improved optimal solution under PSC against P\&O MPPT under same weather conditions.

The BBCSC circuit operated as buck boost and SC circuit separately with two different circumstances with different irradiation values like buck boost consist of high irradiation values in top modules compared to last modules energy transfer in downward path. SC circuit consist low irradiation values in top module, high irradiation in last module energy transfer in upward path. 


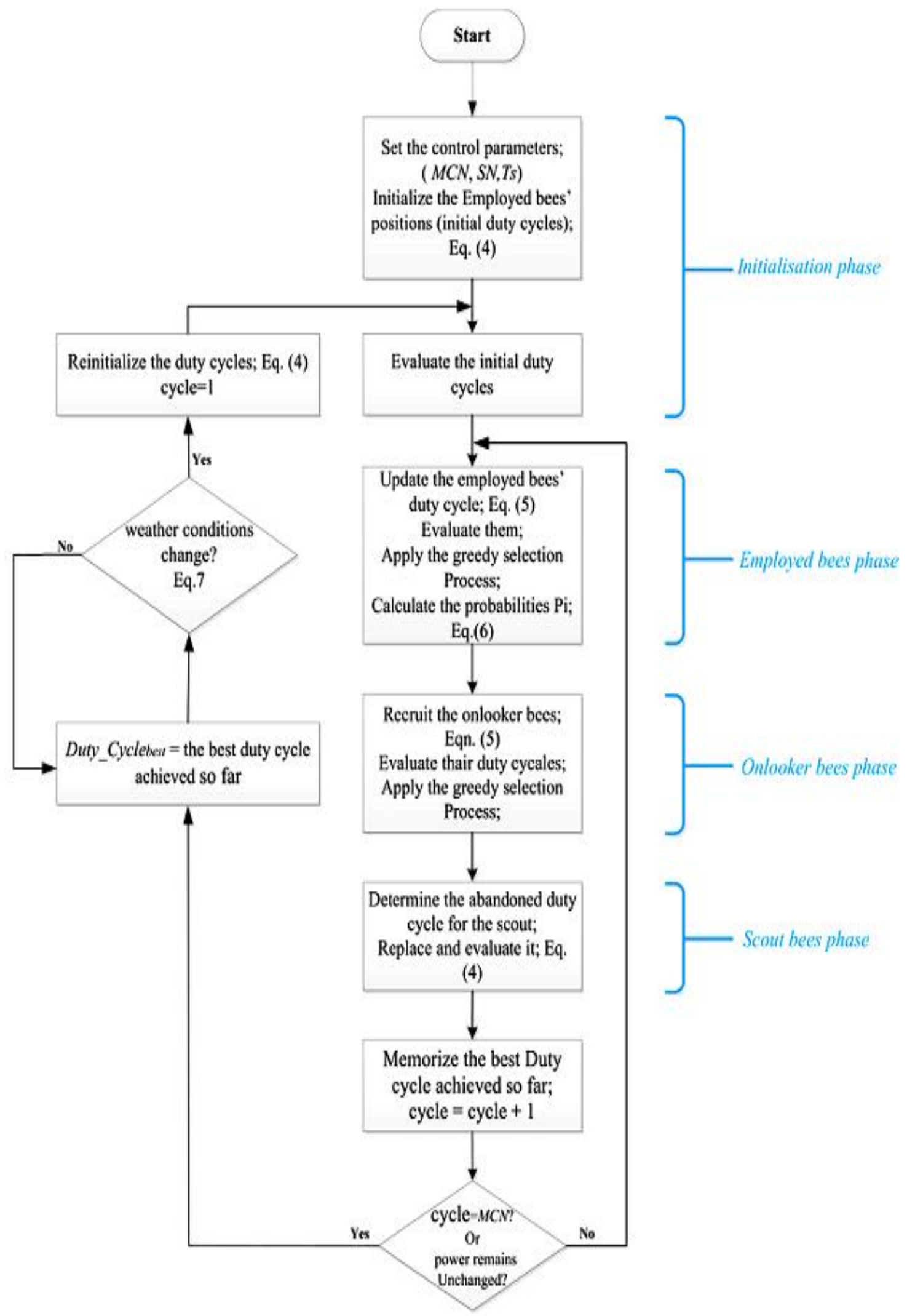

Fig 6. Flow chart of ABC optimization based MPPT 

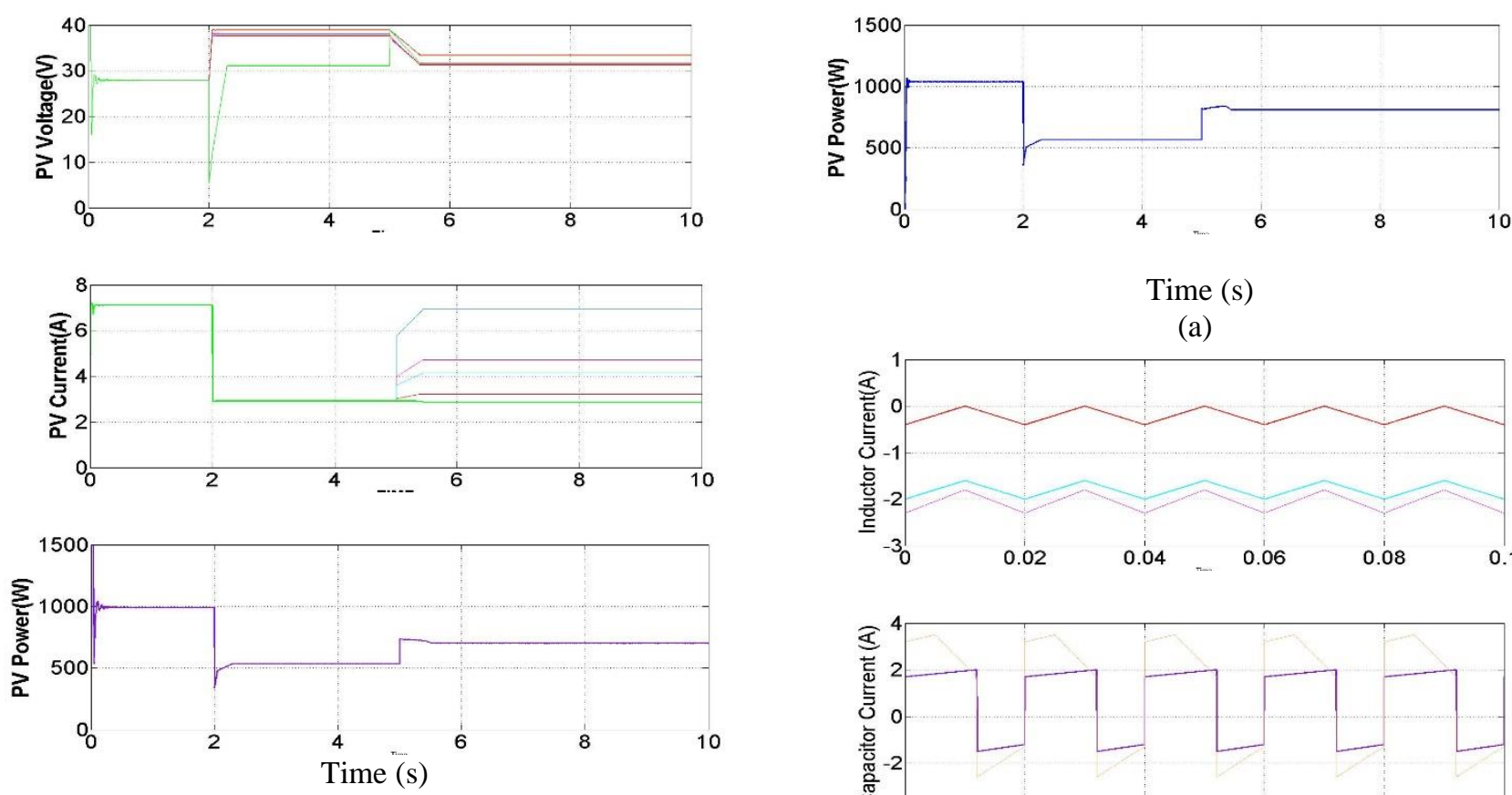

(a)
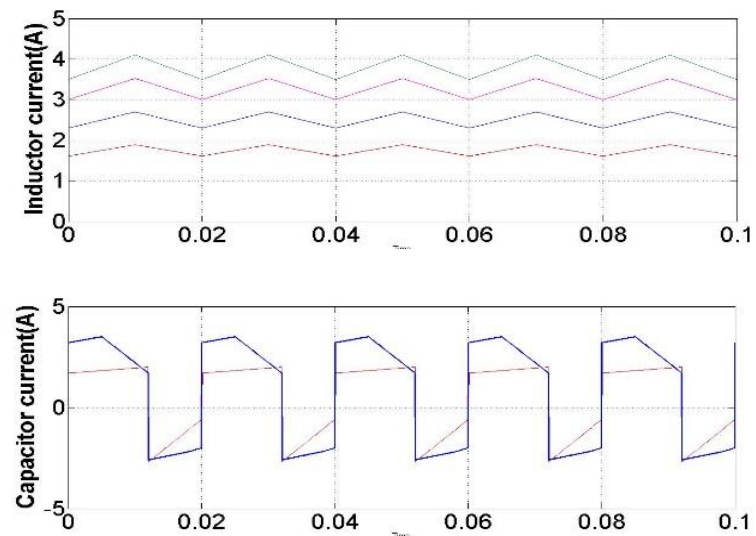

(a) Time(s)

\section{Fig 8.}

Operation of buck-boost converters (from top to bottom): (a) PV modules voltage, PV modules current, and output power of the string; (b) inductors current and capacitors current.
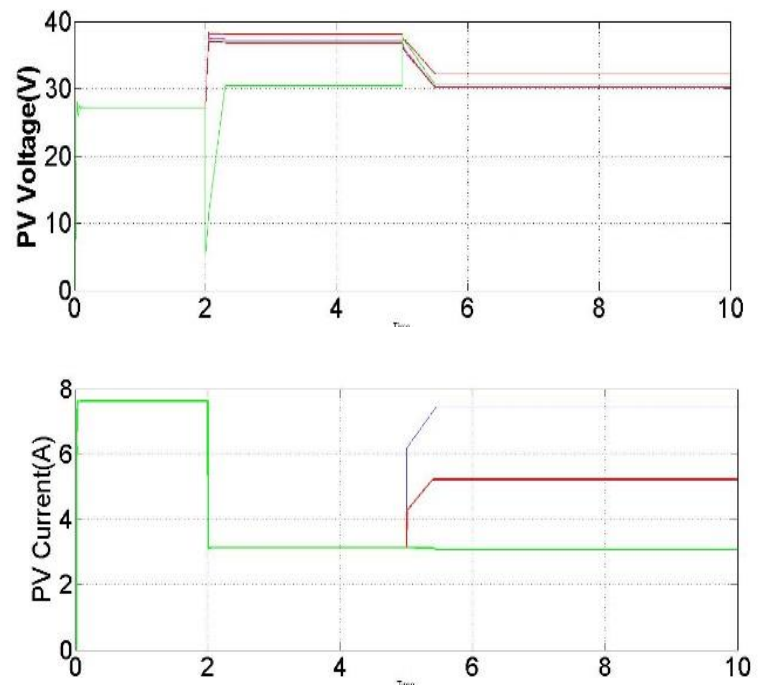

(a)
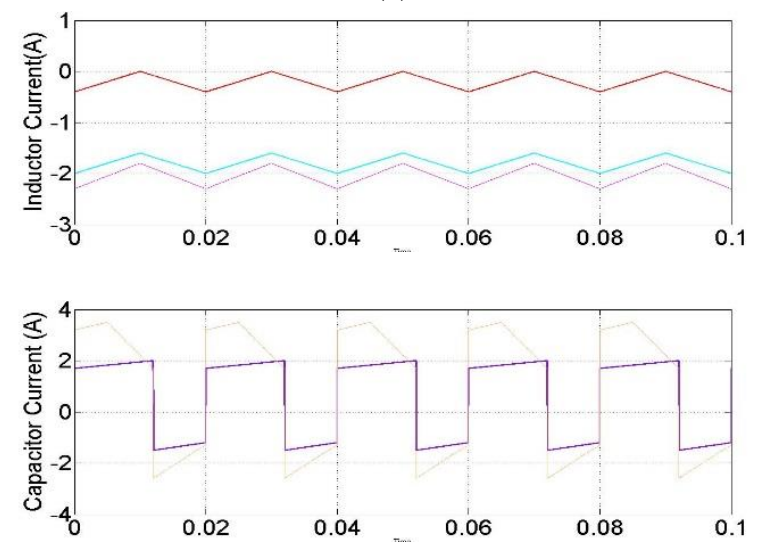

Time(s)

(b)

Fig 9.

Operation of SC converters (from top to bottom): (a) PV modules voltage, PV modules current, and output power of the string; (b) inductors current and capacitors current.

\section{Case 1. buck- boost converter circuit simulation results.}

To observe operation of buck-boost circuit, Consider each PV module with $1000 \mathrm{~W} / \mathrm{m}^{2}$ irradiation under healthy condition. From case $1 \mathrm{t}=0$ to 2 seconds power curve gives 1000 watts with level generated voltage. After $t=2$ seconds PV modules got PSC with different irradiation values. Under shaded condition PV modules current reaches lower value but PV modules voltage nearly same level generate, due to this lower current values power curve shows less value nearly 520W. Energy transfer in downward path from top to lower modules of the PV string. From $t=2$ to 5 seconds BBCSC circuit in turnoff condition. After $\mathrm{t}=5$ seconds gate pulses are given to switches circuit activated, extracted power improved under PSC also with energy recovery circuit. the MPPT set current values as average values. During operation of BBCSC circuit under the shaded condition also total power is increased by $180 \mathrm{~W}$, finally reaches to $700 \mathrm{~W}$ and voltage waveform level generated. Observe inductor and capacitor current wave forms in the simulation results.

Case 2. Switched capacitor circuit simulation results

SC circuit designed to transfer energy from top to lower in upward path like top PV modules have less irradiation compared to lower modules. In case 2 , time $\mathrm{t}=0$ to 2 seconds shows healthy condition of PV modules with same voltage and power. PSC occurs at $t=2$ seconds in the PV string with different irradiation values. Under PSC power also lowered from $1000 \mathrm{~W}$ to $580 \mathrm{~W}$ due to reduced irradiance values. 


\section{Artificial Bee Colony Based MPPT Technique for Solar PV System Under Partially Shaded Condition}

In SC circuit operation $\mathrm{S}_{2}, \mathrm{~S}_{4}$ switches are complementary with $\mathrm{S}_{5}, \mathrm{~S}_{6}$ switches. After $\mathrm{t}=5$ seconds $\mathrm{SC}$ circuit activated with gate pulses. The MPPT takes output current as a average current. Inductor current values also shown in condition after $\mathrm{t}=5$ seconds, power extract from the shaded modules improved by $220 \mathrm{~W}$. power reaches $800 \mathrm{~W}$ from $580 \mathrm{~W}$.voltage waveform also level generated.
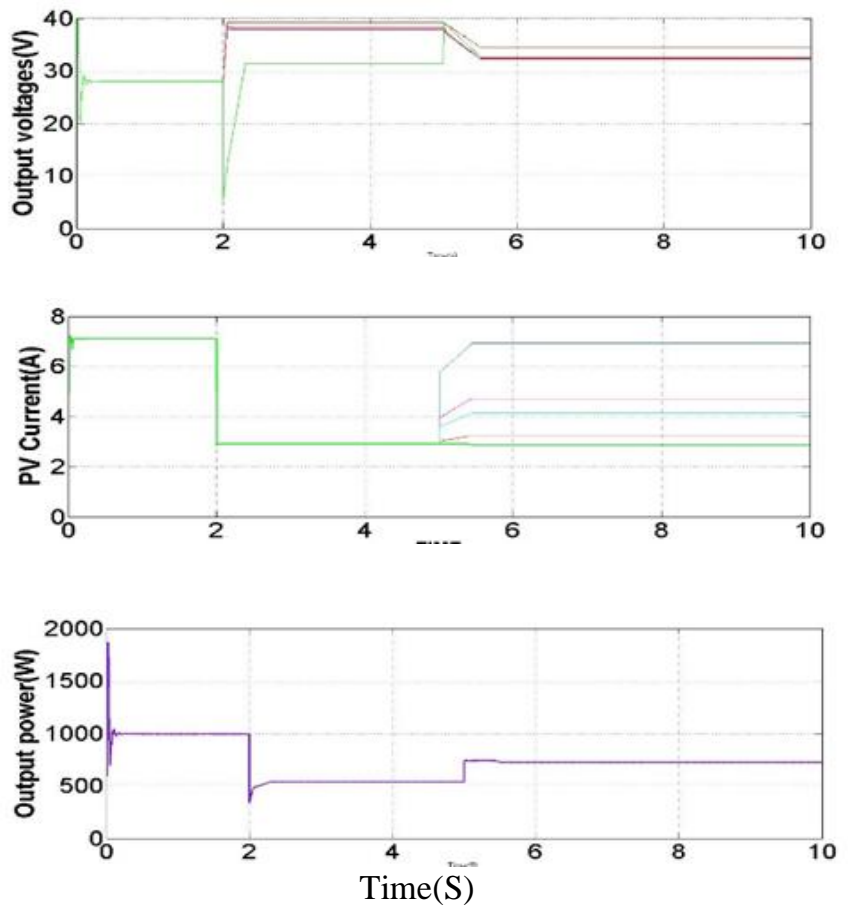

(a)
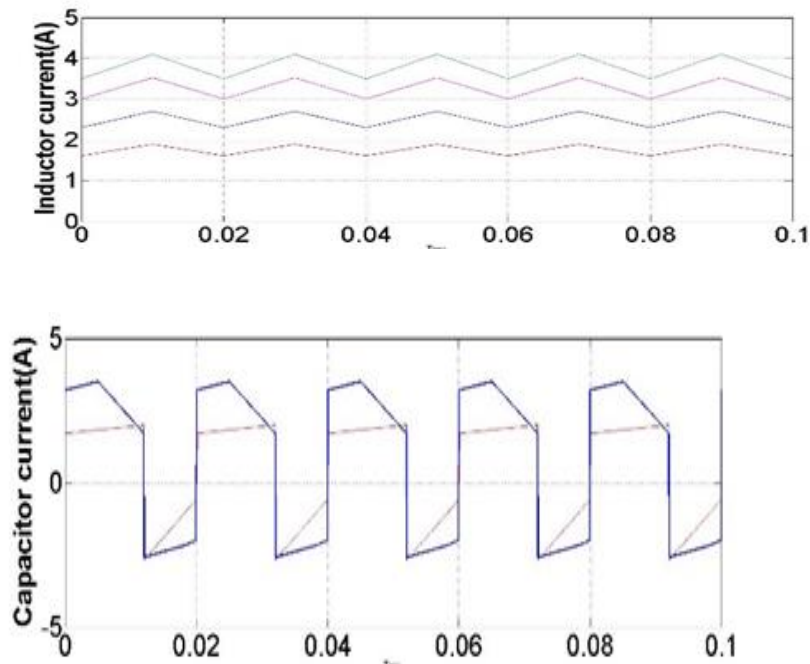

Time(S)

(b)

Case 3.

Operation of buck-boost converters (from top to bottom): (a) PV modules voltage, $\mathrm{PV}$ modules current, and output power of the string; (b) inductors current and capacitors current. negative value manner due to dc offset. In the shaded
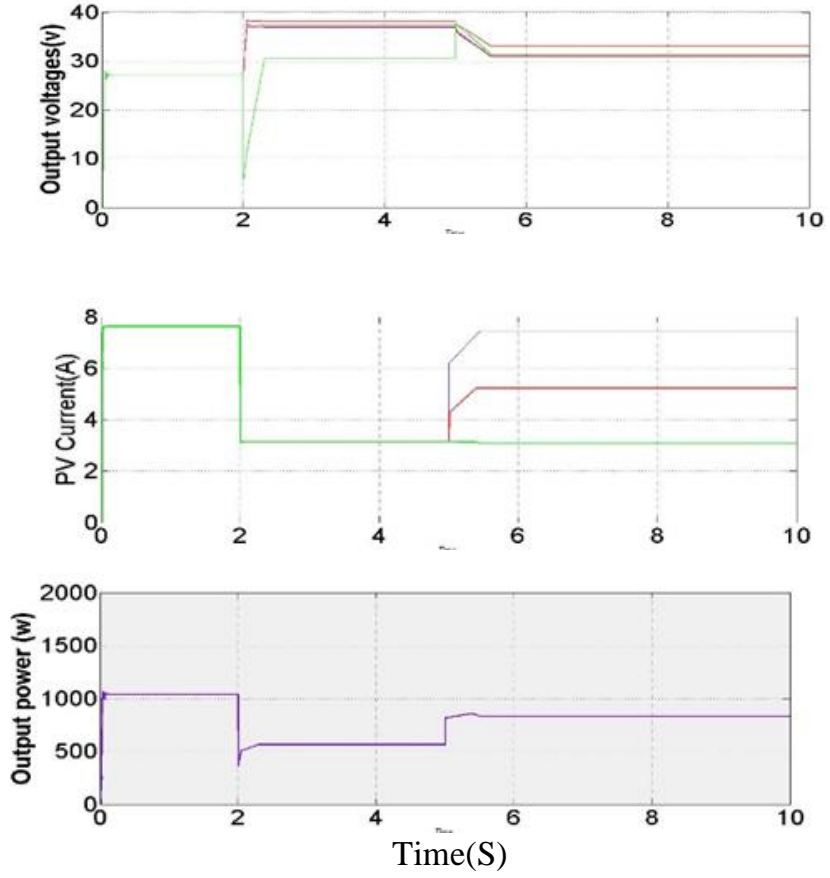

(a)
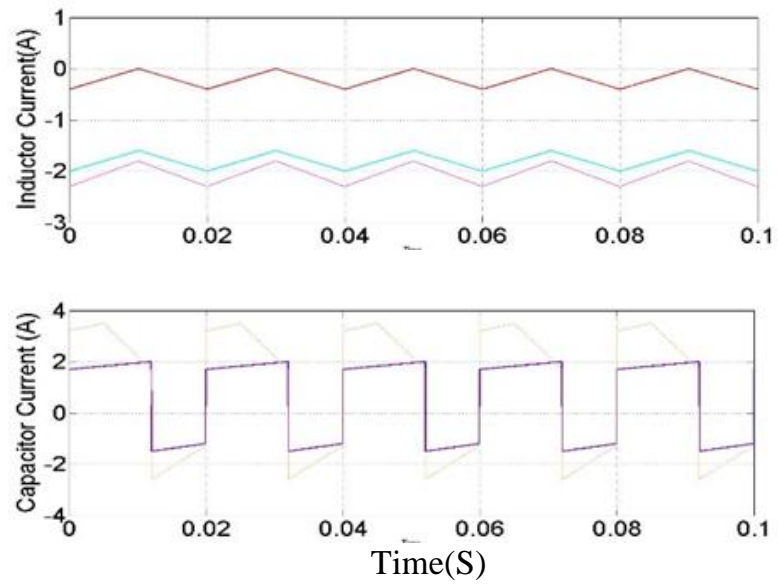

(b)

Case 4.

Operation of SC converters (from top to bottom): (a) PV modules voltage, $\mathrm{PV}$ modules current, and output power of the string; (b) inductors current and capacitors current.

Case 3. In this case, consider buck boost circuit with same weather conditions but conventional P\&O MPPT replaced with optimized ABC algorithm. This algorithm improves MPP of the PV modules in the PSC, maximum output power increased from $700 \mathrm{~W}$ to $720 \mathrm{~W}$ and also improved output voltages level generation. Improved simulation results are shown in case 3 waveforms. apart from waveforms observation optimized technique ABC algorithm improved MPP against P\&O MPPT Case 4. In this case consider SC circuit with same weather conditions but conventional $\mathrm{P} \& \mathrm{O}$ MPPT replaced with optimized ABC algorithm. This algorithm improves MPP of the PV modules increases output power from $800 \mathrm{~W}$ to $830 \mathrm{~W}$ and also improved output voltages level generation.

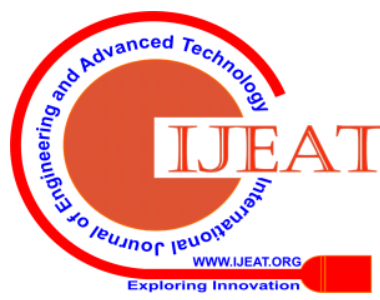


Improved simulation results are shown in case 4 waveforms. from these waveforms proved, optimized ABC algorithm improves MPP compared with conventional P\&O MPPT.

Table-1: Comparison between P\&O MPPT Controller and ABC based MPPT Controller during PSC in Extracted Power(watts)

\begin{tabular}{|c|c|c|c|c|}
\hline \multirow{2}{*}{ PARAMETER } & \multicolumn{2}{|c|}{$\begin{array}{c}\text { P\&O MPPT } \\
\text { CONTROLLER }\end{array}$} & \multicolumn{2}{c|}{$\begin{array}{c}\text { ABC based MPPT } \\
\text { CONTROLLER }\end{array}$} \\
\cline { 2 - 5 } & $\begin{array}{c}\text { BBC } \\
\text { CIRCUIT }\end{array}$ & $\begin{array}{c}\text { SC } \\
\text { CIRCUIT }\end{array}$ & $\begin{array}{c}\text { BBC } \\
\text { CIRCUIT }\end{array}$ & $\begin{array}{c}\text { SC } \\
\text { CIRCUIT }\end{array}$ \\
\hline Power(watts) & 700 & 800 & 720 & 830 \\
\hline
\end{tabular}

\section{CONCLUSION}

In this paper, the proposed BBCSC circuit produces equalized voltage in PV module string, assisted with Artificial Bee Colony (ABC) algorithm is shown better performance characteristics in terms of extracted output power and output level generated voltages. The comparative analysis between the conventional perturbs and observer (P\&O) MPPT and proposed state of art method carried out in simulation results with swarm intelligence optimization ABC algorithm based MPPT, indeed track MPP during PSC with high efficiency.

\section{REFERENCES}

1. M. Z. Ramli and Z. Salam, "A simple energy recovery scheme to harvest the energy from shaded photovoltaic modules during partial shading," IEEE Trans. Power Electron., vol. 29, no. 12, pp. 6458-6471, Dec. 2014.

2. H. Patel and V. Agarwal, "Maximum Power Point Tracking Scheme for PV Systems Operating Under Partially Shaded Conditions," IEEE Transactions on Industrial Electronics, vol. 55, pp. 1689-1698, 2008

3. J. T. Stauth, M. D. See man, and K. Kesarwani, "Resonant switched capacitor converters for sub-module distributed photovoltaic power management," IEEE Trans. Power Electron., vol. 28, no. 3, pp. 1189-1198, Mar. 2013

4. V. Salas, E. Olías, A. Barrado, A. Lázaro, Review of the maximum power point tracking algorithms for stand-alone photovoltaic systems, Sol. Energy Mater. Sol. Cells 90 (2006) 1555-1578.

5. K. Ishaque, Z. Salam, M. Amjad, and S. Mekhilef, "An improved particle swarm optimization (PSO)-based MPPT for PV with reduced steady-state oscillation,” IEEE Trans. Power Electron., vol. 27, no. 8, pp. 3627-3638, Aug. 2012.

6. N. Femia, G. Petrone, G. Spagnuolo, and M. Vitelli, "Optimization of perturb and observe maximum power point tracking method," IEEE Trans. Power Electron., vol. 20, no. 4, pp. 963-973, Jul. 2005.

7. J. T. Stauth, M. D. Seeman, and K. Kesarwani, "A resonant switched capacitor IC and embedded system for sub-module photovoltaic power management," IEEE J. Solid-State Circuits, vol. 47, no. 12, pp. 3043-3054, Dec. 2012.

\section{AUTHORS PROFILE}

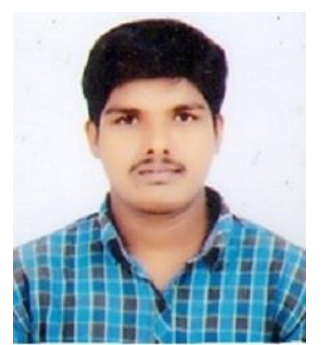

L Venkata Subba Reddy, received his Bachelor's Degree from Yogi Vemana University , Proddatur, india, in the year 2015, from Electrical \& Electronics Engineering. .He is currently working towards his Master's Degree from JNTUA College of Engineering, Ananthapuramu, India, in Power\& Industrial Drives specialization from Department of Electrical \& Electronics Engineering, 2019. In the fulfillment of Bachelor's degree he has done project on "Low Frequency AC transmission for offshore wind power". His research interests are Power Electronic Converters, Renewable Energy Sources and Electric Drives. 